\title{
Policy guidelines suggested for robot-assisted prostatectomy
}

\author{
John R. Valvo • Ralph Madeb · Richard Gilbert • \\ Craig Nicholson · Gregory Oleyourryk · Scott Perrapato • \\ Anthony Ricottone $\cdot$ William Roberts $\cdot$ Louis Eichel
}

Received: 3 June 2007 / Accepted: 15 June 2007/Published online: 31 July 2007

(c) Springer London 2007

One of the innate qualities of all doctors is the desire to do what is best for the ailing patient. This quality then becomes an objective sought by all clinical physicians to improve medical standards as they tryto find better ways of delivering healthcare to their patients. Although incorporation of minimally invasive laparoscopic, robotic, and endo-operative techniques into mainstream care has proved disruptive, our patients are demanding effective yet minimally invasive approaches to their healthcare needs. Accompanying these advances and advantages are the challenges and ethics of applying surgical technology to our respective patients. Currently, in the United States, every individual hospital is required to develop criteria and policies for granting clinical privileges to surgeons operating in their hospital. This task is usually assigned either to the medical director or the chief of each particular surgical service, who verifies whether the respective surgeon is "credentialed" for that procedure. The hospital, compromised by the medical staff office, is, in turn, required by the Joint Commission of Accreditation of Healthcare Organizations (JCAHO) to verify the credentials and training of their

J. R. Valvo · R. Madeb $(\bowtie) \cdot$ C. Nicholson ·

G. Oleyourryk · L. Eichel

Rochester General Hospital, Polisseni Institute for Robotic and Minimally Invasive Surgery, 2615 Culver Road, Rochester, NY 14642, USA

e-mail: RRM@rochester.rr.com

S. Perrapato $\cdot$ A. Ricottone

Mercy Hospital of Buffalo, Buffalo, NY, USA

R. Gilbert · W. Roberts

St Joseph's Hospital, Syracuse, NY, USA practitioners to delineate clinical privileges. One areas in which this process came into existence was credentialing aged surgeons. It is well known that fine motor skills wane as one ages. It was, therefore, recommended that "as age advances, a physician should, from time to time scrutinize impartially, the state of his faculties; that he may determine, bona fide, the precise degree in which he is qualified to execute the active and multifarious offices of his profession" [1]. Clearly, the above-mentioned process that materialized, which is generally standard across the nation, was not designed to address the introduction of new revolutionary surgical techniques and machinery. What remains is the question-how do we credential surgeons with new surgical technology, in particular robot assisted surgery?

Robot-assisted surgery is the application of advanced computerized technology in the planning, performance, and follow-up of invasive surgical procedures. The Food and Drug Administration (FDA) approved the da Vinci robotic surgical system (Intuitive Surgical, Sunnyvale, CA, USA) April 2004 for use in several surgical disciplines, including cardiac, urologic, and gynecologic surgery. The da Vinci telerobotic surgical system consists of a three dimensional laparoscopic vision system and two or three robotic arms that can perform high-precision articulating movements with a variety of instruments. Both the vision system and the robotic arms are controlled by the surgeon in a "master/slave" relationship via a remote surgeon's console that houses the vision system and the telemanipulators for the robotic arms. The technology enables for more precise and anatomical dissection with outcomes equal to or better than conventional techniques in both academic and private practice-based settings [2-6], for both laparoscopic and non-laparoscopic trained surgeons $[7,8]$. 
Robot-assisted surgery is not a mere extension of one's innate ability to perform open or laparoscopic surgery. The appropriate and safe use of this technology requires specialized training and experience. Although the FDA reviews the results of laboratory, animal, and human clinical testing, it does not develop or test products. The FDA does not, moreover, regulate who buys or uses the product, or whether a physician is qualified to use the equipment. The ability to perform a surgical procedure is regulated by hospital-based credentialing policy. Credentialing is the systematic approach to the collection, review, and verification of a practitioner's professional qualification.

Robot-assisted surgery may not be learned safely during a weekend course. Dedication, commitment, and unique cognitive and technical skills are required to transfer skills from an open or laparoscopic setting to a robotic setting. There are no widely accepted guidelines that define appropriate credentialing for robot-assisted urologic surgery. This group was formed in response to a need to establish prudent and fair guidelines for credentialing robotic surgery at our respective institutions.

Electively we tried to formulate a policy for credentialing and maintenance of credentials for robot-assisted radical prostatectomy. The guidelines herein are proposed for obtaining privileges and performing robot-assisted radical prostatectomy using the da Vinci telerobotic surgical system. Use of this technology should be limited to the level of intervention already granted under the same privileges for open and advanced laparoscopic procedures. Special circumstances may arise where robot-assisted surgery may be appropriate for non-laparoscopic open surgical procedures. Credentialing is considered on a case-by-case basis. Our consensus is given in the Appendix.

We believe that every institution that invests in the da Vinci telerobotic surgical system should consider establishing a robot-assisted surgical subcommittee of their existing credentialing committee. As with any surgical procedure, credentialing should be dictated by the policies of the local hospital or institution. To the best of our knowledge, most institutions have embarked on robotassisted surgical programs without the benefit of procedural guidelines for obtaining surgical privileges and credentialing of physicians for robot-assisted surgery because of the newness of the technology. The suggested guidelines can serve as a template to such committees in an effort to provide direction for a successful launch of a new program or facilitation of a successful ongoing program.

Based on a collaborative experience of 1,500 cases and numerous proctoring experiences at various institutions, we recommend the following guidelines. A minimum of four cases be proctored before performing robotic surgery independently. Based on consensus opinion four cases seems practical but each credentialing committee should consider a surgeon's past operative experience and availability of appropriate proctors. More importantly, each proctor and trainee must determine if additional cases may be required before performing these procedures independently.

In an era of evidence-based medicine, surgical competence is being defined by some as a measure of quantity by using "volume" of a procedure to ensure acceptable outcomes. In urology, the prototype has been the conventional radical retropubic prostatectomy [9-12]. Occurrence of postoperative and late urinary complications was reduced if the procedure was performed in a high-volume hospital and by a surgeon who performs a large number of such procedures. However, significant variations occurred among surgeons that suggested technical details were critical for favorable outcomes [9, 10, 12]. In addition, post-operative mortality was low and similar among surgeons and hospitals with different volumes of radical prostatectomies [9-12]. Other disciplines require a minimum number of procedures to obtain and/or maintain surgical privileges, because studies demonstrated that a caseload threshold exists whereby surgical outcomes decline for hospitals or surgeons [11, 13-15]. The Society for Bariactric Surgery requires a 150-case minimum per year/per institution and a 50-case minimum per year/per surgeon for recognition as a center of excellence [11, 13-17]. The American Society for Gastrointestinal Endoscopy (ASG guidelines) recommends a minimum number for each endoscopic procedure performed before competence can be assessed [18]. Although many believe there is inherent quality in quantity, the frequency of a procedure is more than just a marker of quality. Experience gained by repetition may be an underrated aspect of a surgeon's technical ability. We recommend by consensus that a minimum number of robot-assisted cases be performed on an annual basis, although data that enable scientific validation of this opinion are not currently available [12]. Although the benefits of quantity of surgical procedures remain controversial, idle motor skills wane faster than memories.

"Pay-for-performance" may soon require that urologists track outcomes. The higher than expected variability in outcome for radical prostatectomy performed by high volume surgeons led to the appropriate recommendation for monitoring of individual surgeon performance [10, 12]. High-quality surgical care is everyone's objective. Periodic review is mandatory to expose deficiencies and improve quality outcomes. Procedural credentialing is a privilege - not a right that serves to protect patients from practitioners whose skills are less than otherwise available. We suggest these guidelines to assist urologists and their medical institutions with commencing a successful 
and safe transition from open to robot-assisted radical prostatectomy.

\section{Appendix}

Physician credentialing

1. The individual should possess full attending privileges to perform open radical prostatectomy prior to requesting privileges to perform robot-assisted prostatectomy.

2. The physician should show evidence of attendance and successful completion of a hands-on training program in the use of the da Vinci telerobotic surgical system. The program should be at least $8 \mathrm{~h}$ in duration. The physician should have at least $3 \mathrm{~h}$ of personal experience on the system during this course.

3. Evidence of practical experience via an accredited fellowship or residency program and clinical experience in a minimum of 30 computer-assisted procedures utilizing the da Vinci telerobotic surgical system may be substituted for steps 1 and 2 .

4. The physician should show evidence of having observed at least four clinical cases using the telerobotic surgical system.

5. The surgeon should be proctored until the surgeon demonstrates successful use of the telerobotic surgical system and a minimum of four cases should be proctored.

6. In the absence of a credentialed proctor, a second surgeon who has met steps 1-4, may serve as a cosurgeon or as the proctor.

7. It is the responsibility of the applicant to obtain a suitable proctor. The proctor should have temporary OR privileges to enhance the learning experience, and should be appropriately credentialed to serve as a proctor by the computer-assisted surgical committee and the chief of service before serving as a proctor.

8. Requests for privileges should be reviewed by a computer-assisted surgical committee and chief of service, in accordance with the by-laws of the medical staff.

9. Other special circumstances may be considered on a case-by-case basis, subject to the review and recommendation of a computer-assisted surgical committee.

10. To obtain credentialing, a surgeon should expect 20 robot-assisted cases per year.

11. To maintain credentialing, a surgeon should perform 20 robot-assisted cases per year.

12. Interruption of computer-assisted surgery of more than six months should require review of credentialing by a computer-assisted surgical committee.
Surgical assistants (non-physician)

1. The physician to be assisted should have clinical privileges to use the da Vinci telerobotic surgical system.

2. Non-physician staff should be a designated registered nurse surgical assistant (RNSA), nurse practitioner (NP), or physician assistant (PA) with hospital privileges.

3. The surgical assistant should have attended a hands-on training practicum (which can occur on-site at the local hospital) of at least $6 \mathrm{~h}$ duration.

4. The surgical assistant only applies to the bedside assistant. The assistant may not operate the surgical console.

Surgical assistants (attending physicians)

1. The physician should be board-certified, board-eligible within his or her surgical specialty, or a resident/fellow in training.

2. The physician should have hospital privileges and meet criteria as specified in the by-laws of the department of surgery and the medical staff.

3. The surgical assistant must have attended a hands-on training practicum (which can occur on-site at the local hospital) of at least $6 \mathrm{~h}$ in duration.

4. The surgical assistant only applies to the bedside assistant function.

\section{Monitoring}

1. On going clinical monitoring of cases performed using the da Vinci telerobotic surgical system should be conducted.

2. Surgical outcomes should be analyzed periodically.

\section{Recommended}

1. Surgeons should be trained as teams of two individuals.

2. Physicians in each trained team should be able to function as either the surgeon, or assistant.

3. The trained teams can each be used to proctor their counterpart on the team for the purpose of complying with the foregoing policy and procedure.

4. It is preferable to have a specially trained team of operating room personnel, (the robotic team), that 
scrub and circulate on robotic cases given the complexity of the technology and the procedures performed. The "robotic team" model is consistent with the "pump team" for cardiac surgical procedures.

\section{References}

1. Percival T (1803) Medical ethics, or a code of institutes and precepts, adapted to the professional conduct of physicians and surgeons. Johnson \& Bickerstaff, London

2. Ahlering TE, Woo D, Eichel L, Lee DI, Edwards R, Skarecky DW (2004) Robot-assisted versus open radical prostatectomy: a comparison of one surgeon's outcomes. Urology 63(5):819-822

3. Ahlering TE, Eichel L, Edwards RA, Lee DI, Skarecky DW (2004) Robotic radical prostatectomy: a technique to reduce pT2 positive margins. Urology 64(6):1224-1228

4. Menon M, Tewari A, Peabody J (2003) Vattikuti Institute prostatectomy: technique. J Urol 169(6):2289-2292

5. Menon M, Hemal AK (2004) Vattikuti Institute prostatectomy: a technique of robotic radical prostatectomy: experience in more than 1,000 cases. J Endourol 18(7):611-619

6. Tewari A, Menon M (2003) Vattikuti Institute prostatectomy: surgical technique and current results. Curr Urol Rep 4(2):119-123

7. Ahlering TE, Skarecky D, Lee D, Clayman RV (2003) Successful transfer of open surgical skills to a laparoscopic environment using a robotic interface: initial experience with laparoscopic radical prostatectomy. J Urol 170(5):1738-1741

8. Madeb R, Golijanin D, Knopf J, Nicholson C, Cramer S, Tonetti $F$ et al (2007) Transition from open to robotic-assisted radical prostatectomy is associated with a reduction of positive surgical margins amongst private-practice-based urologists. J Robot Surg (in press)
9. Begg CB, Riedel ER, Bach PB, Kattan MW, Schrag D, Warren JL et al (2002) Variations in morbidity after radical prostatectomy. N Engl J Med 346(15):1138-1144

10. Bianco FJ Jr, Riedel ER, Begg CB, Kattan MW, Scardino PT (2005) Variations among high volume surgeons in the rate of complications after radical prostatectomy: further evidence that technique matters. J Urol 173(6):2099-2103

11. Chun FK, Briganti A, Antebi E, Graefen M, Currlin E, Steuber T et al (2006) Surgical volume is related to the rate of positive surgical margins at radical prostatectomy in European patients. BJU Int 98(6):1204-1209

12. Jeldres C, Gallina A, Walz J, Chun FKH, Hutterer GC et al (2007) The effect of surgical volume on the rate of secondary treatment after radical prostatectomy. J Urol 177(Suppl 4):185

13. Chowdhury MM, Dagash H, Pierro A (2007) A systematic review of the impact of volume of surgery and specialization on patient outcome. Br J Surg 94(2):145-161

14. Elting LS, Pettaway C, Bekele BN, Grossman HB, Cooksley C, Avritscher EB et al (2005) Correlation between annual volume of cystectomy, professional staffing, and outcomes: a statewide, population-based study. Cancer 104(5):975-984

15. Gammie JS, O'Brien SM, Griffith BP, Ferguson TB, Peterson ED (2007) Influence of hospital procedural volume on care process and mortality for patients undergoing elective surgery for mitral regurgitation. Circulation 115(7):881-887

16. American society for bariatric surgery's guidelines for granting privileges in bariatric surgery (2006) Surg Obes Relat Dis 2(1):65-67

17. American society for bariatric surgery (2007) http://www.asbs.org/

18. Sharma VK, Coppola AG Jr, Raufman JP (2005) A survey of credentialing practices of gastrointestinal endoscopy centers in the United States. J Clin Gastroenterol 39(6):501-507 